\title{
Fotografia e História: questões teóricas e metodológicas
}

\author{
IVO SANTOS CANABARRO
}

\section{Resumo}

No presente artigo, discutimos questões que tratam da relação da fotografia com a construção do conhecimento histórico, percebendo as dimensões teóricas que delimitam todo um campo de saberes sobre a imagem fotográfica. A utilização da fotografia com seu suporte teórico e metodológico na história é algo muito recente, pois muitos historiadores apenas a utilizavam para a ilustração do texto escrito. Nossa hipótese é que a fotografia pode ser objeto e

Palavras-chave: Fotografia, teoria, metodologia fonte de pesquisa, ao mesmo tempo, um objeto que oferece noções de sua utilização como uma problemática específica no campo da cultura visual. 


\title{
Photography and History: methodological and theoretical issues
}

\author{
IVO SANTOS CANABARRO
}

\begin{abstract}
This article discusses issues related to the relation of photography with the construction of historical knowledge, realizing the theoretical dimensions that encompass a whole field of study about photography. The use of photography with its theoretical and methodological support in history is very recent, as many historians only used it for writing text illustration. Our hypothesis is that photography can be an object and source of investigation and, at the same time, an object that offers notions of its use as a specific problem in the field of visual culture.
\end{abstract}




\title{
Fotografía e Historia: cuestiones teóricas y metodológicas
}

\author{
IVO SANTOS CANABARRO
}

\section{Resumen}

En el presente artículo discutimos cuestiones que tratan la relación de la fotografía con la construcción del conocimiento histórico, observando las dimensiones teóricas que delimitan todo un campo de saberes sobre la imagen fotográfica. La utilización de la fotografía con su soporte teórico y metodológico en la historia es algo reciente, pues muchos historiadores sólo la utilizaban para ilustrar los textos escritos. Nuestra hipótesis en este artículo es mostrar

Palabras clave: Fotografía, teoría, metodología que ella puede ser a la vez objeto y fuente de investigación, ofreciendo nociones de su utilización en cuanto una problemática específica del campo de la cultura visual. 


\section{1 - Introdução: palavras iniciais}

As imagens sempre fascinaram a humanidade. Sendo, inclusive, anteriores à própria escrita. São expressões de sentimentos, demonstração de poder, representações das diferentes formas de os homens se situarem no mundo. Um misto de realidade e realismo com significados instigantes, a cada período histórico adquirindo diferentes significados, pois os imaginários são cambiantes e alteram-se com o passar do tempo. As imagens estão por toda parte do mundo, algumas universalmente conhecidas e cultuadas, outras completamente desconhecidas, mas seu conjunto representa toda uma possibilidade de construção de uma cultura visual e, mais recente, de uma história visual. Não podemos pensar a imagem apenas como um artefato, mas situada em todo o seu contexto de pertencimento, no qual adquire seus significados latentes. Mas as imagens podem adquirir outros significados em diferentes contextos, ou seja, novas interpretações de seus significados adquiridos historicamente.

Não podemos pensar as imagens isoladamente, pois elas pertencem aos contextos. São fruto de todo um trabalho que as torna elementos representativos de questões e posições sociais, construídas ao longo do tempo. Um dos primeiros procedimentos metodológicos utilizados para a leitura das imagens foi pensar seus significados latentes no seu contexto de pertencimento, mas, por outro lado, podemos pensar em outra hipótese, se a imagem estiver em outro contexto. Ademais, as imagens mudam de contexto, basta ver os museus e galerias que as acondicionam e exibem para o grande público. O que nos vem em mente? Que elas não foram feitas naquele espaço e está ali para uma peculiar exibição e contemplação. Portanto, em outro contexto que não é o seu original. Isso já 
nos indica novas possibilidades de leituras, seus significados dentro de uma coleção, de um pintor, de um escultor, de um fotógrafo, de um cineasta, enfim, de quem as produziu com uma determinada finalidade e intenção.

A diversidade das imagens nos impressiona cada dia mais. Podemos até afirmar que o mundo está mais visual, pois a facilidade de produção de imagens é impressionante, não precisa mais ser um artista ou um profissional, qualquer amador pode produzi-las. O século XXI tem nos mostrado a utilização da imagem em diferentes situações, a ponto de tornar-se prova dos acontecimentos cotidianos: tudo pode ser registrado e divulgado, o que torna a cultura visual ainda mais próxima da vida das pessoas. As novas gerações trabalham muito bem com a produção de imagens, os das gerações mais antigas vêm aos poucos se acostumando com as novas tecnologias, que se tornam mais popularizadas. Assistimos a um verdadeiro caleidoscópio de imagens de diferentes focos e situações. Tudo parece ser motivo de registro e o que nos parecia estar mais distante se torna próximo, inclusive com os processos de museus e galerias virtuais, onde as obras mais clássicas da humanidade estão à disposição do grande público ao redor do mundo.

Podemos pensar as imagens em dois grandes grupos distintos: as imagens fixas - escultura, pinturas, grafites e as em movimento - cinema, audiovisual e televisão. As imagens fixas foram as primeiras a serem concebidas, inclusive antes da escrita formal, portanto, constituindo-se como signos plausíveis de interpretações dentro de uma cultura visual. As imagens em movimento são mais recentes, praticamente do final do século XIX com a criação do cinema, depois foram difundidas pelo audiovisual e, um pouco mais tarde, com o fenômeno de massa que foi a criação da televisão, popularizando de vez as imagens em movimento, com circulação e consumo no mundo inteiro. Tanto as imagens fixas quanto as em movimento são plausíveis de diferentes modos de leitura e interpretação, ambas servindo como fonte de objeto dos atuais estudos históricos. Elas constituem uma narrativa visual para a construção do conhecimento, nos dando a possibilidade de múltiplas interpretações de diferentes contextos históricos.

Neste artigo, a abordagem vai se deter num tipo específico de fonte imagética, ou seja, no uso da fotografia como fonte e objeto nos estudos históricos contemporâneos, concebendo-a como uma nova forma de olhar a história a partir das narrativas visuais. Se as imagens já entraram tarde no campo da história, a fotografia é muito recente e merece toda uma reflexão 
sobre as suas possibilidades de adentrar nos diferentes contextos históricos. Estamos falando de uma nova história, de uma história do cotidiano, de uma história cultural que abre as janelas para novos objetos, abordagens e fontes. Neste sentido, as fotografias conseguem ganhar o gosto dos historiadores, que começam a sua utilização como fonte e mesmo como objeto, utilizando a narrativa visual como uma nova possibilidade de narrativa histórica. Podemos constatar que, no caso específico do Brasil, a fotografia já faz parte de nossa experiência visiva praticamente desde o início de sua descoberta em 1840 , pois vieram fotógrafos europeus para retratar o Brasil ainda no período imperial, sendo o país um dos pioneiros a fazer parte do fenômeno moderno da fotografia.

A abordagem escolhida neste artigo perpassa por uma discussão sobre a fotografia nos estudos históricos contemporâneos, contemplando o acolhimento da mesma como fonte e objeto de reflexão para a construção do conhecimento. $\mathrm{O}$ enfoque escolhido foi a partir da história cultural, que abre a possibilidade de acolher as novas narrativas e sensibilidades no campo da história. Para além de uma abordagem teórica, vamos também propor uma metodologia de leitura das fotografias baseada nas noções de planos, já amplamente utilizada na leitura de outras imagens, tanto das fixas como das em movimento. Desta forma, estamos pensando nas fotografias como parte de uma cultura visual, mapeando um campo mais recente de reflexões até se chegar à configuração de uma história visual. Ainda para completar a nossa abordagem teórica e metodológica, vamos fazer a leitura de uma fotografia demonstrando todo o potencial dela para a construção de narrativas visuais, contribuindo, neste sentido, com a apresentação de novas fontes e objetos no atual campo da teoria da história contemporânea, que gradativamente se abre para novas possibilidades de interpretações do passado.

\section{2 - Desenvolvimento}

\section{1 - A fotografia e a teoria}

A fotografia já a partir de 1839 começou a fazer parte da experiência visiva moderna, revolucionando todo o processo de captação de imagens. As experiências começaram antes desta data, mas o culminante foi nesse ano, sendo marcado como a oficialização do daguerreótipo, considerado como a 
"primeira" fotografia. Foi uma descoberta excepcional, pois, a partir desse momento, seria possível captar a realidade com seus múltiplos detalhes. A pesquisa fotográfica foi feita inicialmente por Nicéphore Niépce (1765-1833), juntamente com Louis-Jacques-Mandé Daguerre (1789-1851): ambos trabalharam juntos por muito tempo nas descobertas de captação da imagem mecânica. A descoberta mais significativa feita por Daguerre tratava de colocar vapor de mercúrio numa chapa de iodeto de prata exposta à luz, revelando-se uma imagem latente em tal chapa, sendo o princípio do daguerreótipo. Foi um processo único de captação de imagem numa chapa, e o evento foi patenteado em janeiro de 1839 na França, dando origem às primeiras fotografias modernas.

O daguerreótipo revolucionou a forma de captação das imagens, pois diferente da pintura e da gravura, era um processo mecânico de produção de suportes, capaz de produzir imagens detalhadas e claras de forma totalmente surpreendente. Os pintores e retratistas da época ficaram muito impressionados com a nova técnica, inclusive suscitando o fim da própria pintura de retratos. O daguerreótipo ficou conhecido como "o espelho da memória", exatamente por retratar a realidade com tamanha nitidez de detalhes, o que a pintura não conseguia realizar. Era tido, por essa razão, como uma cópia fiel da realidade: esta foi a primeira série de discursos sobre a fotografia. As fotografias eram tão realistas, que chegavam a assustar os pintores e artistas pelo seu total realismo, mas os daguerreótipos eram cópias únicas, ou seja, não eram reproduziveis, quase uma obra de arte mecânica, mas, por serem muito delicadas, elas exigiam o acondicionamento em um estojo no qual era posta a placa de vidro.

Daguerre, logo após a descoberta, criou todo o mecanismo de captação da imagem, ou seja, uma câmera de captação que poderia ser livremente comercializada, dando origem aos primeiros daguerreotipistas, os quais saíram pelo mundo a captar imagens. No Brasil, Dom Pedro II comprou a câmera e logo começou a produzir daguerreótipos, bem como vieram alguns daguerreotipistas para cá tomando imagens, no princípio, no Rio de Janeiro. Desta forma, pode-se afirmar que o Brasil entrou muito cedo para a história da fotografia, pois também foi palco de produção de imagens mecânicas, fazendo com que o Rio de Janeiro fosse uma das primeiras cidades na América do Sul a conhecer a fotografia. Neste sentido, podemos afirmar que a presença da fotografia no Brasil aconteceu desde os seus primórdios, o que de certa forma pode contribuir decisivamente 
para o conhecimento da experiência visiva moderna. Podemos, inclusive, afirmar, a partir dessa premissa, que temos muitas fotografias no Brasil, e poucos trabalhos que as exploram, razão por que boa parte da história visual brasileira está ainda por ser feita, cabendo a nós historiadores esta tarefa.

Os primeiros fotógrafos foram também os responsáveis pela pesquisa fotográfica, aprimorando o processo de captação das imagens, e mesmo dos equipamentos, que foram aos poucos tomando um novo formato. Fotógrafos como Fox Talbot e Schott Archer, aprimoraram o processo, criando, a partir de 1850 , já o processo de reprodutibilidade da imagem fotográfica, contribuindo decisivamente para a história da fotografia moderna. Foi o conhecido processo do colódio úmido, que permitia espalhar sobre um vidro um material incolor sensível à luz e sem granulações. Era a descoberta do negativo de vidro, utilizado amplamente para a captação da imagem durante a segunda metade do século XIX. Este processo de utilização do negativo de vidro na Europa e Estados Unidos vai praticamente até 188 o quando foi então descoberto o negativo de celuloide flexível. Os processos também se revelaram transformadores nas câmeras fotográficas, com a invenção da máquina portátil; assim, a fotografia se popularizou e se tornou também uma prática dos amadores, marcando uma nova fase na história social da fotografia.

Ao longo do século XIX, a fotografia passou por diferentes transformações, fruto de uma pesquisa intensa por parte dos fotógrafos e da própria incipiente indústria fotográfica, passando de uma atividade singular feita por fotógrafos profissionais para uma prática cotidiana feita por amadores. Mas, no mesmo século assistimos à grande evolução dos estúdios fotográficos, os verdadeiros templos da fotografia da magia a ilusão de se representar, estes, espalhados pelas principais cidades do mundo representavam uma forma fantástica de representação da imagem. Os estúdios eram verdadeiras fábricas de sonhos, nos quais as pessoas buscavam a melhor forma de portar-se no espaço fotográfico, pois contavam com roupas e acessórios que poderiam representá-las como um verdadeiro burguês em sua melhor forma. As pessoas quase que se travestiam de um personagem ideal para uma sociedade capitalista, usando as roupas mais elegantes, e os acessórios mostravam riqueza e poder em cenários típicos da classe dominante. Era uma forma de representação de algo imaginário, elas não eram daquela forma, mas gostariam de serem vistas, assim, como pessoas bem-sucedidas. 
Nas observações de Dubois (1994), a fotografia no século XIX realmente representava um espelho fiel da realidade, era a ordem do discurso, na época, para a ciência, em um primeiro momento distanciando-a da obra de arte. Muitos fotógrafos denominavam de "arte fotográfica" uma forma de manifestação da arte mecânica, mas com a criatividade do sujeito operador da câmera. Isso ficou evidente nas Exposições Universais por todo o mundo: as obras de arte em destaque e as fotografias como primas pobres da arte. A fotografia, desde o seu princípio, foi mais popular do que a obra de arte, quem conseguia um retrato pintado era alguém de um notável poder aquisitivo, e a fotografia era muito mais barata e tornava-se mais acessível com o trabalho dos fotógrafos itinerantes que percorriam as cidades em busca de clientes. Com essa expansão e popularização da fotografia, ela sai dos grandes estúdios da marca dos fotógrafos importantes para tornar-se algo popular e acessível: todos poderiam ser fotografados e ter o seu testemunho visual.

A experiência da fotografia no século XIX, desde os seus primórdios, mostrou uma evolução espetacular nas técnicas de captação da imagem e nos aparelhos fotográficos, os quais tornaram-se mais populares. Passando de uma fotografia profissional para uma fotografia amadora, conseguiu adeptos no mundo todo: desde o começo de sua invenção, os fotógrafos saíram da Europa em busca de imagens que pudessem reportar o conhecimento do mundo para além daquele continente. As imagens capturadas representavam as diferentes culturas ao redor do mundo, os sujeitos sociais, os tipos característicos de cada espaço geográfico, as cidades, os monumentos históricos resultantes da diversidade cultural de cada sociedade retratada. A fotografia foi, e continua sendo, de grande utilidade para a ciência, pois permitiu a captação de diferentes tipos de sujeitos sociais, de animais, de paisagens e da própria natureza exuberante em alguns espaços. No Brasil isso foi surpreendente, pois, com os novos espaços de colonização, vieram os primeiros fotógrafos juntamente aos imigrantes, o que permitiu retratar toda a ocupação social do espaço nas novas áreas de colonização.

Foi a partir de 1880 que a fotografia passou a ser utilizada pela imprensa, o que causou um grande impacto junto aos leitores, pois, ao lado da palavra escrita, tínhamos as imagens para comprovar algumas ideias passadas para o grande público. A partir de então, passou também a fazer parte de livros e revistas ilustradas, criando uma narrativa visual importante para a divulgação da cultura e da ciência. Seu grande triunfo foi real- 
mente no século XX na imprensa, pois os fotógrafos viajavam pelo mundo para trazer imagens fantásticas sobre as realidades para além da vida cotidiana de seus leitores. A história social da fotografia demonstrou, com grandes exemplos, os primórdios da produção das imagens e seu processo lento de incorporação à vida da sociedade moderna. Ela aparece como testemunha das vivências das pessoas em diferentes culturas e sociedades, demonstrando, ao longo de sua história, transformações na forma de captação, produção e consumo. As sociedades modernas utilizam mais a fotografia como testemunha de vida, tanto de uma vida cotidiana, quanto da vida de pessoas importantes retratadas em suas diferentes atividades sociais.

No século XX, a fotografia passou por diferentes fases de expansão. A própria economia industrial impulsionou esta prática no mundo inteiro, com o desenvolvimento da indústria fotográfica contribuindo decisivamente para os equipamentos fotográficos tornarem-se mais populares. Mas os trabalhos dos fotógrafos profissionais mantiveram-se lado a lado com a fotografia amadora, num processo de expansão do campo visual incorporando novos sujeitos retratados. No Brasil, a expansão foi espetacular, pois assistimos a um processo de interiorização da fotografia, que deixa de ser privilégio dos grandes centros urbanos e vai para os lugares mais distantes em busca de retratar a vida social brasileira. Com a intensificação do processo de imigração no Brasil, vieram, juntamente com esses imigrantes, fotógrafos que já exerciam a profissão na Europa, tentando uma nova vida aqui em busca de se estabelecer com o ofício fotográfico. Este fator foi fundamental para a inserção da fotografia nos novos espaços de colonização, pois temos imagens de praticamente toda a construção do espaço social nas áreas de imigração, com ênfase para o Sudeste e Sul do Brasil, regiões que receberam um maior número de imigrantes.

As fotografias, segundo Le Goff (1996), revolucionam a memória, dando um caráter de exatidão que poucas fontes históricas podem oferecer, servindo como uma forma de democratização da memória social. Segundo o autor, trata-se de uma fonte privilegiada para a construção do conhecimento histórico por permitir ir muito além da descrição, trazendo elementos perceptíveis nos suportes fotográficos que testemunham a vida dos homens nas diferentes sociedades. A fotografia, como suporte para a memória social, indica a possibilidade de sua exploração e leitura sistemática para servir como fonte e objeto de estudos; neste sentido, deixando de lado o caráter meramente ilustrativo com que foi utilizada amplamente 
por historiadores que não conheciam o seu potencial latente. As imagens contribuem para a ampliação da visão dos historiadores, pois colocam em cena questões totalmente inéditas que as demais fontes não proporcionam, mostrando algo plausível de interpretações múltiplas que dependem do olhar apurado do historiador. A imagem sempre é múltipla, ou seja, permite uma gama variada de interpretação, cabendo ao historiador adquirir a habilidade de sua leitura.

As narrativas visuais são múltiplas e complexas, pois levam em consideração todo o processo de produção, circulação e consumo da imagem. Em outros termos, as imagens possuem uma história própria, cabendo ao historiador encontrar o ponto de mutação entre um objeto que possui sua história e serve também como fonte o objeto para a construção do conhecimento. Estamos trabalhando numa via de mão dupla, ou seja, de fontes ou objetos que possuem a sua própria historicidade, e isso importa muito no seu processo de leitura: elas não são alheias ao seu processo de criação, pois trazem consigo todo um conjunto de significados que precisam ser desvendados no momento de sua leitura. Somente é possível a utilização das imagens após o seu processo de leitura e interpretação, caso contrário, ela continuaria no seu papel meramente ilustrativo e não como fonte e objeto.

O trabalho de leitura das fotografias pelos historiadores requer todo um conjunto de atenções. Ele precisa perceber historicamente a fonte e o objeto, situando-os em um determinado contexto de pertencimento para que a fotografia possa ser decifrada na plenitude de seus significados. Os fotógrafos e suas imagens pertencem a um determinado período e contexto histórico, pois são produções técnicas e também humanas, chegando-se a afirmar que possuem duas mediações: uma técnica, que é todo o aparato para sua captação, e uma humana, que é a intenção do olhar e o recorte feito pelo próprio fotógrafo. Reforçando essa premissa, pode-se observar, em Frizot (2001), que a fotografia constitui-se como um documento, sendo histórico por natureza, pois o tempo que retrata e as particularidades do instante são fragmentos de uma história geral. Esta é uma das melhores formas de situar a fotografia como documento histórico, pelo seu caráter testemunhal de retratar a própria história em diferentes períodos e situações de vivências dos atores sociais retratados.

O momento decisivo para a utilização das imagens na construção do conhecimento histórico foi a partir da Escola dos Annales, nos anos de 1930, quando assistimos a uma ver- 
dadeira revolução documental. Ao lado dos documentos escritos, as novas narrativas ganharam espaços até então inusitados para essas fontes, com as imagens passando a compor o campo de exploração dos historiadores. Mas as imagens apareceram com um elemento auxiliar na interpretação histórica, elas não ocuparam lugar de destaque como fonte e muito menos como objeto. Como observa Chartier (1993), as imagens passaram a ser apreendidas como documentos históricos, ou seja, as propriedades técnicas, estilísticas e iconográficas ligam-se a um modo particular de percepção e a uma maneira de ver moldada em toda a experiência social. Foi realmente uma revolução documental no sentido literal do termo, pois a incorporação de novas fontes requer todo um conjunto de habilidades dos historiadores na perspectiva de pensar o conhecimento a partir dos desdobramentos de outros olhares, fontes e objetos. A partir da Escola dos Annales, em suas diferentes gerações, o uso das novas fontes foi propagado para muito além da França, conquistando aos poucos o gosto dos historiadores.

A discussão sobre o uso da fotografia para o conhecimento histórico no Brasil é muito recente. Alguns autores, como Boris Kossoy, Maria Inez Turazzi e Ana Maria Mauad são pioneiros nesta discussão, pois incorporaram essa fonte de pesquisa nos estudos históricos brasileiros. Convém ressaltar o texto de Meneses (2003) para reacender a discussão no Brasil. O autor procurou, em seu artigo, detalhar os caminhos do uso das fontes visuais na construção do conhecimento histórico, mostrando as possibilidades e mesmo os limites desta fonte. O próprio autor descreve a importância de se pensar em uma história visual, produzida a partir de documentos visuais, para tentar estudar a dimensão visual da sociedade. Ainda Meneses adverte que o visual refere-se à sociedade e não às fontes especificamente; neste sentido, o objeto é sempre a sociedade, cabendo ao historiador trabalhar com problemas históricos, buscando a solução por intermédio das fontes visuais, juntamente com outras fontes disponíveis para a pesquisa.

A história visual, assim, é entendida como próxima da cultura visual, pois o diálogo sempre se mostrou muito produtivo em busca de resultados satisfatórios para responder às interrogações dos historiadores. Neste sentido, Knauss (2006) faz um balanço muito preciso acerca da cultura visual e como a mesma foi pensada por diferentes correntes teóricas até chegar a tornar-se objeto do conhecimento. Parece que a discussão tomou corpo no Brasil, pois começaram a surgir trabalhos que atestam a importância da história visual como campo do conhecimento 
capaz de nos mostrar os desdobramentos daquilo que possa ser concebido como visual. O entendimento do visual é um exercício para situá-lo como parte integrante das próprias relações sociais, uma produção dos atores que se preocupam em registrar algumas dimensões de vivências nos suportes visuais, sejam analógicos ou digitais, para contemplar a produção mais recente de imagens na sociedade contemporânea.

Mas a maior inspiração sobre o uso da fotografia para a produção do conhecimento histórico vem da França mesmo, com a Terceira Geração da Escola dos Annales, fonte que entrou decisivamente para os Estudos Históricos. Historiadores dos Annales, como Le Goff e Nora (1995), atribuem a esta geração a propagação do uso da fotografia como documento histórico, aproximando-a da história social da fotografia, ou seja, o uso consciente de uma fonte que tem a sua própria historicidade, um documento carregado de história. Le Goff (1995) observou com nitidez a importância da fotografia para o conhecimento histórico, ressaltando que é um dos grandes documentos para a história: por consistir de prova de que algo aconteceu, a fotografia permite conhecer a riqueza da vida, mesmo sendo realista, porque o próprio realismo é uma construção. Ela representa uma inegável expressão do indivíduo e, também, uma expressão da vida cotidiana das pessoas. Neste sentido, podemos perceber que a riqueza da fotografia consiste em ser uma testemunha do que aconteceu, realista e imaginária ao mesmo tempo.

Nas observações de Nora (1997), a fotografia, desde os anos de 1970, começou a fazer parte da oficina da história, com o seu potencial criador e diferenciado dos documentos escritos, conquistando os historiadores por acrescentar novas dimensões à história. O autor observa o alargamento da história dando mais atenção às novas fontes; no caso específico do arquivo visual, o mesmo entrou definitivamente para a preocupação dos novos temas historiográficos. A noção de testemunha passa a ser concebida como uma noção de traço, e o não escrito começa a dilatar o domínio da história. A fotografia passa a ser percebida como um instantâneo extraído do movimento permanente, uma mostra representativa da realidade, um analogon do que foi o passado, uma relação de descontinuidade decorrente da mistura de distância e aproximação, portanto, sendo uma possibilidade de documento histórico.

No Brasil, temos os trabalhos pioneiros de Boris Kossoy, que desde a década de 1980 vem se dedicando ao tema com muita propriedade, trazendo para o campo da história uma discussão pertinente sobre os usos da fotografia para a construção 
do conhecimento. Kossoy (1989) faz uma separação fundamental para o entendimento do campo de estudos. Ele faz uma divisão entre a história da fotografia e a história pela fotografia. No primeiro caso, salienta que é o estudo sistemático da fotografia como meio de comunicação e expressão em seu processo histórico, afirma que é importante conhecer os artefatos representativos dos diferentes períodos, a tecnologia utilizada e os estilos e tendências de representações vigentes em um determinado período histórico. Também considera fundamentais as circunstâncias ligadas ao processo que originou a imagem, como também o seu uso enquanto testemunho visual em suas diferentes aplicabilidades nos períodos históricos.

No segundo caso, da história pela fotografia, é o emprego da fotografia do passado nos diferentes gêneros históricos e mesmo em outras áreas da ciência, nas quais os pesquisadores venham a utilizar desta fonte plástica como instrumento de apoio à pesquisa e de conhecimento visual do passado. Ele ainda salienta que as duas distintas vertentes de investigações têm em comum a própria utilização dos documentos fotográficos como fontes básicas para a pesquisa. Neste sentindo, entrecruzam-se, respeitando obviamente os objetos específicos da investigação de cada uma das vertentes. As reflexões de Kossoy influenciaram toda uma geração de historiadores que se aproximaram do campo visual, mais especificamente os interessados em trabalhar com fotografias para a construção do conhecimento histórico no Brasil.

As discussões no Brasil prosseguiram com Mauad (1996). Em um texto totalmente inédito, a historiadora fez uma reflexão sistemática com uma nova vertente de conhecimento no campo da historiografia. O texto aponta dois caminhos que podem ser seguidos: numa primeira direção, seria retomar a história da fotografia, salientando que, além do inventário sistemático das técnicas, tem-se buscado compreender a inserção social da imagem. Para tanto, a autora discute o que se convém chamar de circuito social da fotografia, salientando que este compreende todo o processo de produção, circulação e consumo das fotografias. O segundo caminho sinalizado por Mauad é de compreender o lugar da fotografia na história. A mesma autora prossegue até o momento atual discutindo a importância da fotografia para a história, com artigos e livros relevantes nessa área do conhecimento. São trabalhos inéditos que conseguem repercutir o estado da fotografia em seus diferentes usos na reflexão da produção e aplicabilidades, tanto como fonte de pesquisa, como também objeto do conhecimento histórico. 
Podemos ainda encontrar, na obra de Leite (1993), uma excelente reflexão sobre a fotografia em suas possibilidades, e mesmo limites, no emprego para a construção do conhecimento histórico. A autora salienta existirem claramente duas correntes historiográficas: uma considera que o documento fala e que a imagem fotográfica transmite clara e diretamente informações, e outra concebe as imagens fotográficas enquanto representações que aguardam um leitor para decifrá-las. Neste sentido, a autora observa que a bibliografia a respeito da interpretação da fotografia não é extensa e que muitos trabalhos se detêm na história da técnica, na biografia dos fotógrafos, na multiplicação da arte fotográfica ou na recuperação da verdade. Raros são os estudos do significado e do sentido cultural das imagens. Por fim, a autora salienta que é preciso um estudo comparativo de sistemas de significados das mediações entre a realidade que se quer compreender e a imagem dessa realidade.

A fotografia exige uma reflexão extremamente afinada para a leitura dos seus significados e utilização na produção do conhecimento. Suas diferentes perspectivas de análise apontam para a importância de seu entendimento dentro de um campo de ação, tanto na sua produção, como no seu consumo e aplicabilidades. Mas podemos constatar que a fotografia se insere em um determinado momento da história e, ao mesmo tempo, serve como fonte para a sua reconstituição. Neste sentido, About e Chéroux (2001) concebem, teoricamente, que a história poderá cruzar a fotografia, pois esta é constitutivamente histórica, dando uma forma tangível aos fatos e registrando elementos do passado, isto é, um ar, um olhar, uma tensão, que os outros documentos dificilmente contemplam. Isso atesta o caráter documental da fotografia em sua relação com a história, pela sua riqueza de detalhes que podem elucidar as formas de vivências dos atores sociais em diferentes sociedades representadas em sua forma visual, sendo o visual uma forma de apresentação/representação do passado.

A concepção mais relevante de uma história social da fotografia perpassa pelo entendimento de que a fotografia é essencialmente um produto social, portanto, uma construção carregada de significados. O consumo da fotografia por diferentes grupos sociais pode também revelar a sua própria identidade, portanto, é um dos elementos visuais que possibilita a afirmação de identidades e representações. Frizot (2001) vai afirmar que é preciso conceber uma história social da fotografia separada da história da arte, admitindo que a história da arte já celebrou os grandes nomes de artistas e tendências 
quase generalizadoras. Por essa razão, é preciso pensar numa história social da fotografia pesquisando a atuação de todos os fotógrafos, sejam os mais celebrados, sejam os anônimos, pois todos contribuem para a construção de um campo visual. Temos que recolher as imagens fotográficas não apenas como uma vaga colocação de imagens no mundo e procurar saber as motivações e intenções presentes no momento de sua produção. Neste sentido, podemos observar que é quase um trabalho de garimpo de imagens fotográficas, pois, além das clássicas coleções presentes em arquivos especializados, podemos ainda contar com imagens avulsas produzidas por fotógrafos anônimos e/ou itinerantes que percorreram os mais distantes espaços no processo de interiorização e popularização da fotografia, tanto no exterior quanto no Brasil. No Brasil esta foi uma prática muito constante, pois contamos com muitos fotógrafos que percorreram as diferentes regiões levando a fotografia até os lugares mais desconhecidos.

Ainda seguindo as observações de Frizot (2001), ele concebe a fotografia como documento e, especificamente, um documento histórico, pois pode ser datada e constituída, com as particularidades do instante de tomada; neste caso, representa um fragmento da história geral e um índice provante. Ele ainda discute que, para alguns, a fotografia é uma visão objetiva do mundo, uma maneira de inventariar, enquanto, para outros, é uma visão totalmente subjetiva. Nesta perspectiva histórica, o fotógrafo é visto como um artista que compõe a fotografia com a realidade e desta se apropria a fim de melhor mostrar a si mesmo. Para o mesmo autor, é preciso desacreditar nessa dicotomia documento/arte para melhor insistir no efeito das variedades das práticas e sobre os usos intencionais que sustentam a produção das fotografias. A partir desses pressupostos, podemos concluir que sempre é necessário pensar na historicidade do documento fotográfico, pois o mesmo constitui-se em determinados contextos sociais mediados pelas relações dos grupos que procuram se representar pela fotografia, portanto, por um documento que em dado momento vem à luz.

Frizot (2001) entende com clareza, em sua extensa obra, que a fotografia, para ser analisada, depende de outra mediação, estabelecida individualmente e concebida pelos autores sob um ponto de vista que é histórico. Neste sentido, confrontando o olhar do fotógrafo e do espectador em diferentes variações temporais e espaciais, adentrando no campo das representações visuais, podemos constatar que apresentam diferentes significados ao longo de sua historicidade. Ele chama 
a atenção também para o papel do fotógrafo enquanto produtor da imagem, situando a obra deste em seu tempo, não apenas como continuidade, mas como uma certa arqueologia de toda a produção, a tecnologia empregada e a linguagem fotográfica de uma determinada época. É preciso também perceber as implicações e ações dos fotógrafos em um determinado momento, no sentido de observar como a sociedade, em sua totalidade, é implicada pela fotografia e como os fotógrafos selecionam ou exacerbam as modalidades de ser dos atores sociais ou das situações fotografadas.

Trazendo para o Brasil as discussões que tratam a fotografia e os fotógrafos como parte integrante do trabalho de leitura e interpretação da imagem fotográfica, podemos encontrar ainda as reflexões de Turazzi (1998), que propõe o entendimento do que poderia ser configurado como uma cultura fotográfica. Essa noção contemplaria que a cultura fotográfica como uma das formas de cultura, evidenciada pelo argumento de que a fotografia foi e ainda é um recurso importante e eficaz para a formação do sentimento de identidade, tanto individual quanto coletivo. Igualmente, é um dos meios que materializam a visão de si, para si e para o outro. A cultura fotográfica possui um grau de complexidade, por sua abrangência em uma determinada sociedade, que compreende os produtores das imagens, ou seja, os fotógrafos e sua bagagem profissional, incluindo os equipamentos e as escolhas formais e estéticas e as diferentes tecnologias empregadas na produção das imagens. A mesma noção ainda contempla a importância da fotografia como uma prática social, incorporada há mais de um século e meio ao modo de como se representa o mundo e a nós mesmos. Portanto, apresenta-se como uma possibilidade de compreensão da imagem fotográfica em diferentes sociedades, levando em consideração a diversidade dessa prática no Brasil, com grandes acervos fotográficos espalhados por todo o território nacional.

Os estudos mais recentes, na história visual e mesmo na cultura visual, consideram a fotografia como uma representação visual, capaz de ser lida e interpretada a partir dos significados latentes da imagem. São correntes distintas no exterior e aqui no Brasil; uma considera a fotografia como um signo, e outra como um produto cultural. Podemos observar, em Dubois (1994), uma evolução no sentido de interpretação da fotografia, com a primeira classificação dos discursos, que considera a fotografia como espelho do real, sendo essa uma ilusão da realidade, um duplo. O autor afirma que, no sécu- 
lo XIX, concebia-se a fotografia como uma imagem formada pela máquina sem a interferência do homem, desprovida da subjetividade e da intencionalidade do produtor. Os discursos elucidavam que o efeito de realidade ligado à imagem fotográfica foi atribuído à semelhança da foto com seu referente. A fotografia era considerada um analogon objetivo do real.

Ainda seguindo Dubois, já no século XX a fotografia foi vista de outra forma: deixa de ser um espelho real para transformar-se em uma transformação do real, essa seria a segunda ordem de um discurso que tenta situá-la em um determinado contexto de pertencimento. É uma série de discursos que sustentam a hipótese do código e da desconstrução, encontrando na França um terreno muito fértil para o seu desenvolvimento. Nesses discursos já havia uma crítica quanto à mimese e a transparência da fotografia, ela já se portaria como uma transformação, por ser codificada socialmente. Assim, a fotografia já se portaria como portadora de códigos, sejam eles técnicos, culturais, estéticos e sociológicos. Essa corrente de pensamento não encontrou muito eco no Brasil, pois é uma tendência mais ligada à sociologia da imagem, apresentando restrições quanto a uma leitura histórica da fotografia.

A terceira ordem dos discursos sobre fotografia, segundo Dubois, é a mais recente e remonta às últimas décadas do século XX. Foi a que mais encontrou respaldo no Brasil, pois concebe a fotografia como uma representação visual. Nessa terceira ordem, a fotografia é um traço do real, destacando o discurso do índice e da referência. A análise da fotografia nessa corrente deve essencialmente avançar para muito além da simples denúncia do efeito do real. Assim, é possível a interrogação da própria ontologia da fotografia, considera a fotografia como procedente da ordem o índice (representação por contiguidade física do signo com o seu referente) distinguindo-se dos discursos anteriores, pois considera que a imagem fotográfica é dotada de todo um valor singular, visto ter uma relação com seu referente que deu origem, e por assim dizer, um traço do real. A fotografia como índice pode ser pensada como uma representação visual do seu referente, concebida como uma construção em um determinado tempo e espaço.

Essa corrente teórica e metodológica que defende a fotografia como um traço do real, portanto, como uma representação visual, tem uma grande aceitabilidade no Brasil. Autores de diferentes áreas, como a história, a antropologia, a sociologia e a comunicação, social trabalham de uma forma interdisciplinar apostando nessa configuração sobre a fotografia. Os historia- 
dores no Brasil que trabalham com fotografias para a construção do conhecimento, procuraram uma aproximação com a história, com a cultura visual, e as novas tendências da história cultural. O grande desafio parece ser a configuração mais ampla da história visual no Brasil, pois, com os grandes acervos fotográficos, foi possível pensar em todo um processo de utilização da imagem nos estudos históricos. Segundo Meneses (2003), pensar em uma história visual no Brasil parece ser um desafio contemporâneo, pois o visual apresenta múltiplas possibilidades de construção do conhecimento. O autor ainda observa que os historiadores que trabalham com acervos fotográficos estão bem atentos para pensar a questão da visualidade, pois os acervos permitem ir muito além de meras descrições e adentrar em um campo com múltiplas possibilidades.

Propomos aqui uma possível aproximação da história visual/cultura visual com a história cultural, pois entendemos que é possível trabalhar com o visual, objeto por excelência da história visual e da cultura visual, com a noção de representação visual, objeto da história cultural. Por essa hipótese, podemos pensar nessa aproximação para dar conta dos usos da fotografia para a construção do conhecimento histórico em suas diversas e possíveis abordagens, de modo que possam contribuir para o historiador fazer uma reflexão mais sistemática sobre esse tema, o qual vem conquistando cada vez mais adeptos no Brasil. Entendemos que trabalhar com a visualidade requer todo um cuidado quanto à sua aplicabilidade, pois os objetos não estão soltos, eles fazem parte das relações sociais, da própria vida dos atores que protagonizam, nas diferentes sociedades, sua experiência visual. Aqui retomamos Meneses (2003), pois o visual deve servir com uma entrada para a vida social, para as relações e ações em determinadas sociedades, mas pode ser também pensado como fonte e possível objeto de investigações de um saber que é essencialmente histórico.

A noção de representação aparece na história cultural com as discussões de Chartier (1989), que a considera fundamental para o entendimento do universo cultural, tendência essa seguida por outros autores da história cultural, como Hunt (1992) e Burke (2000), que discutem em diferentes proporções sobre como o universo cultural é permeado pelas representações. Chartier afirma que a representação pode ter dois tipos de significados: primeiro, a representação como substituição por uma forma de representar a ausência; segundo, a representação como exibição, demonstração, adição entre a representação e o representado, exibição de poder e identida- 
de. Para Chartier (1999), a história cultural é uma modalidade que procura entender a produção de sentido das palavras, das imagens e dos símbolos e busca, também, a reconstrução das práticas culturais em termos de recepção de invenção e de lutas de representações. Nesta perspectiva, nos mostrando algumas dependências da vida cultural que aparecem nas diferentes formas de apropriação, mediadas pela representação.

Os estudos em história cultural são bem diversificados, com influências bem significativas da antropologia, da literatura e da semiótica, configurando um campo bem interdisciplinar na decifração dos significados culturais dos objetos. Para Burke (2000), os estudos sobre cultura na historiografia já aparecem desde a década de 1920, quando a cultura parecia ser propriedade de alguns grupos sociais que detinham o poder de afirmar a sua identidade. Já a partir da década de 1940 havia toda uma crítica à história cultural clássica, sugerindo a importância em se considerar as relações entre a cultura e as demais instâncias do mundo social. As críticas também eram relativas à noção de unidade ou consenso cultural, era precioso refletir sobre as contradições sociais que intervêm diretamente na noção de cultura. Atualmente existe toda uma crítica, dentro da história cultural, de relativização do conceito de unidade cultural, sendo preciso essencialmente pensar numa noção de diversidade cultural.

Os atuais estudos em história cultural evidenciam a relação da cultura com o universo social. Segundo Bouza (2001), é preciso pensar nas múltiplas relações que a cultura estabelece com a sociedade, pois a cultura não é uma instância separada, mas uma construção social. No bojo da história cultural, aparecem as representações e as apropriações como conceitos-chave; neste sentido, queremos afirmar que o nosso recorte específico, no caso o uso da fotografia, remete a um tipo especial de representação, ou seja, a representação visual. No complexo universo das representações, o visual aparece como uma forma de entendimento do próprio mundo social, permeado pelas práticas culturais, muito presentes nas fotografias. As imagens fotográficas, consideradas em todo o seu processo de produção, circulação e consumo, podem ser objetos de uma história cultural, se concebidas como produtos sociais que refletem as diversas dimensões de vivências dos atores sociais em uma determinada sociedade. Neste sentido, entendemos que é possível uma aproximação da história visual com a história cultural, a fim de criar instrumentos teóricos e metodológicos para a leitura e interpretação das imagens fotográficas. 


\section{2 - A fotografia e a metodologia}

Existem no Brasil e no exterior várias metodologias para leitura de fotografias, pois, segundo o referencial teórico que cada pesquisador utiliza, é possível também desenvolver uma determinada forma de leitura e interpretação. Podemos contar, no Brasil, com o pioneiro trabalho de Mauad (1996), que já propunha uma leitura da fotografia a partir da noção de espaços na imagem, um trabalho metodologicamente inovador, pois permitia uma leitura dos elementos internos da imagem. Mas os trabalhos se propagaram aqui e fora, a exemplo do mais recente livro de Salkeld (2014), recentíssima obra em que o autor propõe uma leitura da imagem em seus signos, perpassando algumas possibilidades inovadoras na interpretação da fotografia. Nas observações de Leite (1993), a autora já apontava que cada pesquisador propõe uma leitura baseada em toda a sua bagagem de pesquisa, lançando um olhar inovador sobre a imagem.

Levando em consideração a noção de espaço fotográfico, baseado em Dubois (1994), sendo aquele que deve ser capturado, um levantamento no mundo, uma subtração que opera em bloco, este espaço é sempre um limite capturado pela lente do fotógrafo, que faz um recorte de uma determinada realidade em um espaço e tempo limitados. O espaço fotográfico permanece ali no suporte de uma imagem, um recorte para sempre na memória de quem possa ver e interpretar. O espaço fotográfico pode ser desvendado a partir dos planos que o compõem, os quais estão presentes, tanto nas imagens fixas, quanto nas em movimento, é uma linguagem que expressa a sua composição em diferentes formas e sentidos. Por isso, propomos uma leitura da imagem fotográfica a partir da noção de planos; neste caso, respeitando a própria composição delas.

A noção de planos, segundo Zuaneti e Martins (2002), permite situar a figura em relação ao fundo, observando todos os elementos que compõem o espaço fotográfico. Desta forma, conforme Canabarro (2011) trabalhamos com os seguintes planos para a leitura das fotografias:

1 - Primeiro plano: composto pelas figuras humanas que fazem parte da cena retratada, analisando a maneira como se posicionam, inclusive a pose e os gestos, bem como as vestimentas e acessórios, realçando assim as pessoas em um caráter humanista da fotografia.

2 - Plano de detalhes: propicia a ênfase dos elementos significativos da imagem fotográfica, permitindo a análise direcionada ao objeto de investigação. 
3 - Plano de fundo: composto pela área que fica atrás das figuras retratadas, em que o fechamento da lente utilizada permite aprofundar esse plano, ou seja, a profundidade de campo.

4 - Plano geral: conjunção de todos os planos anteriores, permitindo analisar a harmonia e a disjunção entre a cena, o cenário e os dispositivos técnicos utilizados pelo fotógrafo.

A noção de planos apresentada é mais uma possibilidade na leitura das fotografias, observando que é preciso fazer uma relação entre os dispositivos técnicos, os dados internos da imagem e a coleção. A fotografia não é um fragmento isolado da sociedade, ela pertence a todo um conjunto de dados e representações: por isso, quanto mais dados obtivermos sobre o fotógrafo e a coleção à qual pertence, maior a possibilidade de sua leitura. Mas podemos decifrar os significados internos da imagem numa perspectiva de situá-la em seu contexto de pertencimento; em alguns casos, temos poucos dados sobre a mesma, ainda assim, uma leitura de seus planos permite um entendimento de seus significados.

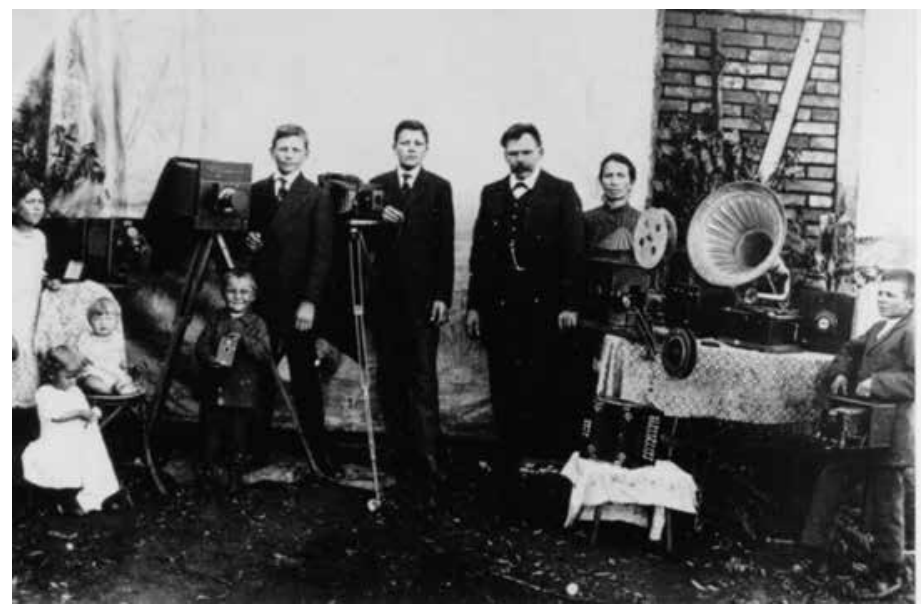

Essa imagem fotográfica, de 1923, pertencente à Coleção Família Beck, reproduzida a partir do negativo em vidro ${ }_{13} \mathrm{X}_{18} 8$ $\mathrm{cm}$, encontra-se no acervo de imagens do Museu Antropológico Diretor Pestana em Ijuí/ RS, devidamente catalogada e disponível para consultas no referido museu. Embora essa imagem seja de 1923, o fotógrafo ainda usava negativos em vidro, pois eram perfeitos para a reprodução e retoques na imagem, processo esse muito utilizado pelo fotógrafo Carlos Germano Beck. A Família Beck atuou profissionalmente como fotógrafos por quase um século na Região Noroeste do Estado do Rio Grande do Sul, 
possuíam um ateliê fotográfico na cidade de Ijuí e, também, trabalhavam como itinerantes percorrendo toda a região. O ofício da fotografia passou de pai para filhos, foram duas gerações de fotógrafos que produziram um acervo considerável de imagens. Os negativos em vidro e flexíveis pertencem atualmente ao acervo do Museu Antropológico Diretor Pestana, que criou a coleção da família, com um número muito expressivo de imagens, negativos e equipamentos fotográficos.

No primeiro plano, a família do fotógrafo ocupa o espaço cenográfico do estúdio ao ar livre. Os personagens posicionam-se em semicírculo, construindo uma cena familiar e profissional ao mesmo tempo. O filho mais velho ocupa o centro da imagem, posicionando-se à direita do seu pai, e os mais novos às margens. As roupas dos retratados são mais sofisticadas, propicias para a cena, o pai e os rapazes mais velhos de terno, e os demais filhos com vestimentas próprias para serem exibidas em ocasiões especiais. No plano de detalhes, os instrumentos de trabalho, câmeras grandes e pequenas, tripé, mesa, instrumentos sonoros, enfim, os equipamentos dos fotógrafos utilizados para o seu ofício. Os gestos e as atitudes dos retratados relacionam-se às atividades que desempenham com os devidos instrumentos, identificando-os com as atividades desenvolvidas pela família. O plano de fundo é limitado pela parede da casa, uma casa estilo enxaimel, muito típica das cidades onde houve colonização alemã. A parede foi coberta pelo painel fotográfico, muito utilizado nos trabalhos como itinerantes, pois criava um estúdio ao ar livre, aproveitando-se da iluminação natural para a produção das fotografias. No plano geral, evidencia-se uma imagem com um excelente enquadramento, utilizando-se de todo o espaço fotográfico para a encenação da família identificada com sua atividade profissional.

\section{3- Conclusão: palavras finais}

O universo da fotografia adquire cada vez mais adeptos, pois, com a crescente popularização dos instrumentos para a captura da imagem, atualmente nos meios digitais, ela adquire novos significados no seu circuito social. A produção, a circulação e o consumo das imagens atingiram uma capacidade surpreendente no século XXI, com alguns autores já afirmando que a comunicação tornou-se imagética, dada a sua capacidade de expressão de sentimentos, sensações e conhecimento. Isso tudo afetou diretamente a produção do conhecimento histórico, pois os historiadores não podem ficar alheios aos 
acontecimentos: como as imagens ganham uma importância muito grande, é de se pensar como a história vai incorporar essa nova realidade. São grandes produções de imagens, numa velocidade maior, tornando o mundo ainda mais imagético, isso tudo refletindo na forma como nós vemos a realidade e, principalmente, como tudo isso afeta o ofício do historiador.

Já estamos vivendo uma época de superação dos limites das fontes históricas. Atualmente, muitos profissionais, acadêmicos e não acadêmicos, se aventuram a construir o conhecimento histórico, é o surpreendente avanço da história pública, que conquista o gosto do grande público leitor. Por isso, dilatando a noção de fonte e mesmo de objeto, as fotografias aparecem com um grande potencial de expressão de realidades e, ao lado das demais fontes, formam um universo de representações a serem incorporadas pela história. Por muito tempo, no Brasil e mesmo no exterior, ela aparecia apenas como uma forma de ilustração do texto escrito, não figurando como fonte e muito menos como objeto de estudos. Nos dias atuais, a reflexão sobre o campo da história torna-se múltipla em todos os sentidos, motivo pelo qual a utilização de uma gama bem variada de fontes é uma tarefa fundamental para a construção do conhecimento. Para tanto podemos contar com pressupostos teóricos e metodológicos que permitem a incorporação da fotografia no campo da história, com resultados mais surpreendentes.

Os historiadores que teorizam sobre a fotografia ganharam um espaço significativo no campo da história, estão aliados a profissionais de outras áreas e a formação de equipes interdisciplinares para a leitura e interpretação da fotografia. São trabalhos inéditos que podem contribuir significativamente no avanço das reflexões históricas, trazendo para os pesquisadores de diferentes áreas sinais evidentes da importância da imagem na leitura da realidade. A França foi pioneira nestes estudos sobre a fotografia, até mesmo pela particularidade de a fotografia ser uma invenção daquele país, o que a colocou à frente das reflexões mediante publicações que evidenciam seus usos sociais e aplicabilidades na produção do conhecimento. Mas essa tendência ganhou o Brasil, também, sendo incorporada sua reflexão por historiadores e demais cientistas sociais que fazem uso dessa fonte privilegiada de conhecimento. No Brasil já existem instituições e laboratórios em universidades que tratam da conservação e usos sociais da fotografia, o que significa um grande avanço nas ciências sociais e, no caso específico da história, propicia a conquista de novos adeptos entre as novas gerações de historiadores. 
Os trabalhos mais metodológicos da leitura e interpretação das fotografias são igualmente bem variados, pois mui-

tos historiadores estabelecem um olhar específico sobre a imagem, que reflete um conjunto de conhecimentos teóricos. Neste sentido, faz-se uma reflexão que parte de um conjunto teórico até o estabelecimento de metodologias mais adequadas, pois é preciso que a cada momento este aporte teórico dê conta dos significados da imagem. Cada metodologia existente aqui no Brasil e no exterior reflete diferentes realidades e especificidades, pois as coleções fotográficas existentes são bem variadas e merecem um olhar que atenda às suas especificidades. Disso tudo resulta a reflexão de que é preciso pensar as fotografias dentro de seu contexto de pertencimento, com atenção para os elementos que as tornam singulares, e que dependem de cada fotógrafo e das suas respectivas coleções, de cada historiador e suas respectivas concepções.

\section{Referências}

ABOUT, Ilsen, CHÉROUX, Clément. L'histoire par la photographie. In: Études photographiques. n.10, Paris: Société Française de Photographie, 2001.

BOUZA, Fernando. Una historia cultural do siglo de oro. Madrid: Marcial Pons, 2001.

BURKE, Peter. A Escola dos Annales (1929 - 1989). São Paulo: UNESP, 1991.

. Variedades da história cultural. Rio de Janeiro: Civilização Brasileira, 2000.

CANABARRO, Ivo dos Santos. Dimensões da fotográfica no Sul do Brasil. Ijuí. RS: UNIJUI, 2011.

CHARTIER, Roger. A história cultural entre práticas e representações. Lisboa: Difel, Rio de Janeiro: Bertrand Brasil, S.A, 1990.

A história hoje: dúvidas, desafios, propostas. In: Estudos históricos. v.7, n.13. Rio de Janeiro, 1994. Le monde comme représentation. Paris: Annales ESC, 1989.

. Verbete Imagens. In: BURGUIÈRE, André. Dicionário das ciências históricas. Rio de Janeiro: Imago, 1993, p.407.

DUBOIS, Philippe. O ato fotográfico e outros ensaios. Campinas, SP: Papirus, 1994.

FRIZOT, Michel (Org). Histoire de Voir. Paris: Nathan/Centre national de la photo, 1989. 
Nouvelle histoire de la photographie. Paris: Adan Biro/ Larousse, 2001.

. Du bom usage de la photographie. Paris: Centre national de la photo,1897.

HACKING, Juliet (Ed.). Tudo sobre fotografia. Rio de Janeiro: Sextante, 2012.

HUNT, Lynn (Org.). A nova história cultural. São Paulo: Martins Fontes, 1992.

KNAUSS, Paulo. O desafio de fazer história com imagens: arte e cultura visual. In: Artcultura, v.8, n.12. Uberlândia, MG: Edufu, Janeiro - Julho, 2006.

KOSSOY, Boris. Fotografia E história. 2.ed. São Paulo: Ateliê Editorial, 2001. . Realidades e ficções na trama fotográfica. São Paulo: Ateliê Editorial, 1999.

- Dicionário histórico-fotográfico brasileiro. São Paulo: Instituto Moreira Sales, 2002.

LE GOFF, Jacques. A história do quotidiano. In: DUBY, George (et.al). História e nova história. Lisboa: Teorema, 1986.

História e memória. Campinas, SP: UNICAMP, 1996.

. Mirages de l'histoire. In: La Recherche Photographique, n.18. Paris: Paris Audiovisuel, 1995.

; NORA, Pierre. História - novos problemas, novas abordagens, novos objetos. Rio de Janeiro: Francisco Alves, 1995.

LEITE, Miriam Moreira. Retratos de Família: Leitura da fotografia histórica. São Paulo: EDUSP, 1993.

MAUAD, Ana Maria de S.A. Essus. Sob o signo da imagem: a produção da fotografia e o controle dos códigos de representação social pela classe dominante no Rio de Janeiro na primeira metade do século XX. Niterói, UFF, Programa de Pós-Graduação em História Social, 1990, 2 v. ( Tese de doutorado).

Através da Imagem: Fotografia e história - Interfaces. In: Revista Tempo, v.1. Universidade Federal Fluminense, Departamento de História. Rio de Janeiro: Relume-Dumará, 1996, p. 73 -98.

MENESES, Ulpiano T. Bezerra. Fontes visuais, cultura visual, história visual. Balanço provisório, propostas cautelares. In. Revista Brasileira de História. v. 23, no 45. São Paulo: ANPUH / Humanitas Publicações, 2003. p. 11-36.

NORA, Pierre. Historiens, Photographes: Voir et Devoir. In: CAUJOLLES, Cristian (dir.). Éthique,esthétique, politique. Arles: Actes Sud, 1997. 
SALKELD, Richard. Como ler uma fotografia. São Paulo: Gustavo Gili, 2014.

SENAC, DN. Fotógrafo: o olhar, a técnica e o trabalho. /Rose Zuanetti; Elizabeth Real, Nelson Martins (et.al). Rio de Janeiro: Ed. Senac Nacional, 2002.

TURAZZI, Maria Inez. Poses e trejeitos - a fotografia e as exposições na era do espetáculo. Rio de Janeiro: Roço, 1995. Uma cultura fotográfica. In: Revista do Patrimônio Histórico e Artístico Nacional. n.27. Brasília: IPHAN, 1998.

Recebido em: 18/o1/15

Aceito em: 21/03/15 


\section{IVO SANTOS CANABARRO}

icanabarro@yahoo.com.br

É pós-doutorando em História na UFF - Universidade Federal Fluminense. Doutor em História Social pela UFF e UP3 - Universidade de Paris III. Professor adjunto na UNIJUI, RS, docente no PPGD em Direitos Humanos. 